HSS VI.1 (2017)

DOI: $10.1515 /$ hssr -2017-0006

\title{
Social and Cultural Barriers in Translation
}

Dominica E. Ukpong*

University of Uyo, Nigeria

\begin{abstract}
There are barriers that translation must scale through to be effective, some of which are social and cultural. Social and cultural differences exist between and amongst nations. In most cases too, we find a country having several social/cultural diversities. These differences impede, in one way or the other, effective translation because of varying conceptions of reality occasioned by languages. This article examines some of the barriers that arise in the course of translation as a result of social/cultural factors. Bringing these barriers into the foray of discussion will also serve as a way of avoiding them.
\end{abstract}

Keywords

Barriers, Translation, Society, Cultural, Reality, Diversities, Differences, Manipulation.

\section{Introduction}

Culture wields enormous influence on man as it is the foundation of his existence, since a person is born into a culture. Every community or nation has its own indigenous culture; this culture defines and shapes a people's perspective about every segment of life. This is why culture is seen as "the way of life of a people, including their attitudes, values,

\footnotetext{
* Department of Foreign Languages, University of Uyo, Uyo, Nigeria; email: nkoyodomi@gmail.com
} 
HSS, vol. VI, no. 1 (2017): 77-87

beliefs, arts, sciences, modes of perception and habits of thought and activity" (Blackburn, 2009: 86).

There is a social angle to culture; every culture therefore takes into cognizance the social dimension and live interactions of a people. In the first place, a culture is practiced within the ambience of a collection of people. Thus, since there is a society, there must of necessity be a social habitat. To this end, social facts are pockets of the awareness of a people's way of life. Durkheim, in corroborating this truth, opines that:

There are ways of acting, thinking and feeling which possess the remarkable property of existing outside the consciousness of the individual. Not only are these types of behavior and thinking external to the individual, but they are endued with a compelling and coercive power by virtue of which, whether he wishes or not, they impose themselves upon him (Durkheim, 1973: 51).

The terms social and cultural can therefore be understood as possessing a link to each other in the sense that cultural activities are meaningful as social significance. Translation, therefore, becomes effective and meaningful as a social tool. If this is the case how can it be influenced socially from a cultural point of view? How can social and cultural factors affect effective translation? How can such factors be resolved and in what ways can the effects be cushioned? These are some of the issues that this paper will attempt to resolve. But let us start by making some conceptual clarifications.

\section{Why Translation?}

Translation Studies is a specialized discipline that is saddled with the responsibility of ensuring that words and texts are replicated in their original and exact forms. This will definitely involve linguists and theorists at the same or different times. However, there does not seem to be much cooperation between these two as noted by Bell:

The translation theorists, almost without exception, have made little systematic use of the techniques and insights of contemporary linguistics (the linguistics of the last twenty years or so) and the linguists, for their part, 
HSS, vol. VI, no. 1 (2017): 77-87

have been at best neutral and at worst actually hostile to the notion of a theory of translation (Bell, 1991: xv).

This polarization has not actually aided progress in translation especially when the goal of translation is "the transformation of a text originally in one language into an equivalent text in a different language retaining, as far as possible, the content of the message and the formal features and functional roles of the original text (an informal definition which will be much modified...) (Bell, 1991: xv).

Translation, therefore, strives for mastery, it strives for exactitude, competence, and perfection of some sort without which it will not be translation. Perhaps this informs the reasons why Ukpong sees it as “... the live wire in complex human-social relationship... the go between two huddles or barrier to communication". Even though the term translation involves several meanings, Munday gives us a comprehensive perspective to it when he asserts that:

It can refer to the general subject field, the product (the text that has been translated) or the process (the act of producing the translation, or otherwise known as translating). The process of translation between two different written languages involves the translator changing an original written text (the source text or ST) in the original verbal language (the source language or SL) into a written text (the target text or TT) in a different verbal language (the target language or TL) (Munday, 2005: 4-5).

From the submission of Munday, as regards what constitute translation, we can now appreciate the "why" of translation. Translation is important for so many obvious reasons as it has as its major task, the preservation of words and texts in their original form after undergoing some language procession. This may not be easily done except when certain variables are considered; this is why the field of translation studies is still evolving, bringing up new ways and method(s) of effective translation especially within the complex society we have today. We shall discuss more about this, but let us move on to examining what social/cultural considerations entail. 


\section{Social/Cultural Mix}

The term social and cultural seem inexorable; when we talk about the word social, we are looking at the big picture of society. The word is often contradistinguished from "individual". On the other hand, "cultural" is the word culture and it has to do with the totality of a people's way of life. Thus in the Longman Encyclopedia, culture is:

The collection of meanings, values, morals, modes of thinking, patterns of behavior, idioms of thought, of speech, ways of life, etc that identify a particular nation - state, group, or social category (1989: 271).

Culture therefore is all-encompassing, touching the very fabric of human cohesion. It is also dynamic, thus undergoing changes. Cultures influence one's behavior and it can also be influenced by internal external factors such as migration, scientific and technological inventions. A change in belief systems may also bring about a change in culture.

A social relation is carried out within a culture, leading to social actions. Social actions are the interaction with other people and are of a primary importance. There are also actions in which the agent is a plurality, a "we" rather than an "I"; it is tempting to reduce this latter category to an aggregate of individual actions, but this kind of reduction or decomposition is not in general available.

Man is a social animal who relates with other humans in groups. The society where man lives is complex, based on the culture that influences social relations/actions. Blackburn opines that:

...how much in the way of social bonding should emerge from our interactions with each other? Language, money and law,... are social entities, dependent on society for their existence and their function? (Blackburn, 2009: 77).

Any setting where there is interaction among individuals can be taken as a society. For it is in a society that communication takes place, for which we need language, even transactions whereby goods and services are traded for other goods and services, for which we eventually need 
money; and of guidelines for behavior and sanctions for trespass, for which we need law. Hence, "we have a set of structures, or in other words, individuals bound to each other in complex webs of relationships. And that is what is meant by a society" (Blackburn, 2009: 78).

\section{Social/Cultural Dimension to Translation}

Since translation is a human activity, and humans are social/cultural animals, then translation must have a social/cultural dimension. Humans communicate in words and text; hence language is a medium of communication invented by man to foster harmonious social relationship and co-existence. To this end, there is a need for mastery of language; and this involves not only the ability to understand immediately, an indefinite number of entirely new sentences, but also the ability to identify deviant sentences and, on occasion, to impose an interpretation on them. To Chomsky, therefore, the central fact to which any significant linguistic theory must address itself is this:

A mature speaker can produce a new sentence of his language on the appropriate occasion, and other speakers can understand it immediately, though it is equally new to them. Most of our linguistic experience, both as speakers and hearers, is with new sentences. (Chomsky, 1964: 50).

A translator or interpreter cannot divulge him/herself from the nitty gritty of mastery in language if he or she must be an effective translator. $\mathrm{He} / \mathrm{she}$ must keep pace with good knowledge of the language in question and even from cultural dimensions to semantics and syntax. At the level of cross-cultural translation, there is a need to pay greater attention to cultural diversities and the role they play in the determination of truth via language. This is where such linguistic appellations like idioms, proverbs, collocations, riddles and so on come into play, so that a word could earn something entirely different from its translation. In this case, should the translator rest content on the degree of closeness or equivalence? Newmark gave some translation procedures; under cultural equivalent, he contends that "cultural equivalents are usually inaccurate but they are a shorthand, have emotional force, are useful for immediate effect on the receptor, e.g. in 
the theatre or cinema (subbing or sub-titling), and they transport the readership uncritically into the TL culture" (Newmark, 2001: 30).

The social/cultural dimension to translation also challenges the proficiency of translators to effective translation and competence because of the depth of knowledge of the language to be unearthed. This is because, "translating involves not just two languages, but a transfer from one culture to another" (Hervey and Higgins, 2007: 28). It therefore follows that since translation has a social/cultural angle, as it has been established, it becomes a conditio-sine-qua-non for this social/cultural dimension to be studied and properly contextualized. If this is done, it becomes easier for the barriers that will hinder effective translation to be removed; and this shall be our next focus.

\section{Removing Social/Cultural Barriers to Translation}

Since the words or texts to be translated are situated or housed in a culture which has social significance, it becomes imperative for the translator to have adequate knowledge of the culture via whose language of which he/she desires to work. Since language is a highly complex phenomenon produced by incredibly complex human beings, Shastri's averment below becomes really instructive:

It is complex at all the levels such as sounds, words, semantics and pragmatics. Complexity increases with the use of idioms, metaphors, proverbs and the highly stylized language of literature because of poetic license that the writers take. Besides, the author works under the spell of inspiration, which the translator has to artificially create. Hence, translating is more difficult than the original writing (Shastri, 2012: ix).

It is important to stress the major issues raised by Shastri some of which are: poetic license, spell of inspiration, and artificial creation. Of course, every writer has some or all the freedom to build castles with words; that is called poetic license. In the employment of this license, the use of idioms, metaphors, proverbs and so on can be freely applied. This license also can dovetail into inspiration that is uniquely his. The challenge there is the burden of having to read the author's or writer's mind. All the option that may be opened to the translator is to artificially 
create or close gaps because "there is no art to know the mind's construction in the face" as opined by Shakespeare. It is in this sense that translation becomes really difficult than just writing originally.

Hervey and Higgins actually discovered that there are more cultural issues in translation and wondered whether it is to be compromised or compensated. The authors used the general term "cultural transposition" (2007: 28) as a cover-term for the various degrees of departure from literal translation that one may resist to in the process of transferring the contents of a ST into the context of a target culture. That is to say that, the various kinds of cultural transposition they discussed are all alternatives to a maximally SL-based literal translation. They opined that:

Any degree of cultural transposition involves the choice of features indigenous to the TL and the target culture in preference to features with their roots in the source culture. The result is to minimize 'foreign' (that is, SL-specific) features in the T'T, thereby to some extent naturalizing it into the TL and its cultural setting (Hervey and Higgins, 2007: 28).

The various degrees of cultural transposition can be seen as points along a scale between the extremes of exoticism and cultural transplantation.

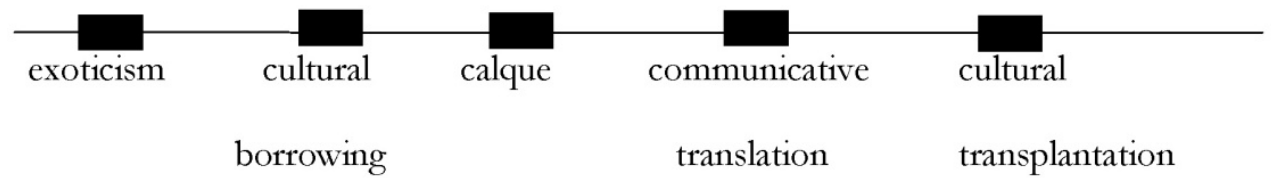

In translating names for example (place-names and proper names) should the name be taken over unchanged from the ST to the TT, or can it be adapted to conform to the phonic/graphic conventions to the TL? The first alternative is tantamount to literal translation, which is less extreme: here conversional/conventions are used to alter the phonic/graphic shape of a ST name so that it comes more into line with TL patterns of pronunciation and spelling. This is the standard way of coping with Chinese names in English texts. But we have a little problem as brought forward by Hervey and Higgins "how a name is transliterated 
HSS, vol. VI, no. 1 (2017): 77-87

may be entirely up to the translator, if there is no established precedent for transcribing the name in question, or it may require following a standard transliteration created by earlier translators" (Hervey and Higgins, 2007: 29).

A further alternative in translating names is cultural transplantation; this is the extreme degree of cultural transposition. SL names are replaced by indigenous TL names that are not their literal equivalents, but have similar cultural connotations. Cultural transposition is not without its risky option as well. If this is the case, what should one bear in my mind when translating names? Hervey and Higgins give the following advice:

When translating names, one must, therefore be aware of three things: first existing options for translating a particular name; second the implications of following a particular option... and third, all the implications of a choice between exoticism, transliteration and cultural transplantation (Hervey and Higgins, 2007: 30).

What we have merely observed is the cultural angle to names (placenames and proper names). The problem can also be applied to other cultural issues apart from names; and the difficulty will still be present. It becomes obvious, therefore, that translation is fraught with compromise. And as Hervey and Higgins further opine, "compromise in translation means reconciling oneself to the fact that, while one would like to do full justice to the "richness" of the ST, one's final TT inevitably suffers from various translation losses" (Hervey and Higgins, 2007: 34).

These losses seem to be sacrificed on the altar of clear meaning in prose or in the case of verse, metric and phonic effects. But the question that keeps begging for an answer is: "is this compromise itself not an evidence of the ineffectiveness of the translator? The translator may succeed in removing the social/cultural barrier to translation, but has he gained effectiveness, efficiency, productivity or professionalism? These shall be the focus of our evaluation. 


\section{Evaluation}

One of the serious burdens that translators will have to come to terms with is that there is compromise in translation. Irrespective of the justification, such a compromise only exposes a lacuna. There may also be arguments pushed forward in defense of a compromise, one of which will be: we can't have a perfect translation. If translation cannot be perfect, what will be the standard by which "enough is enough"? What can be described as good translation? Newmark advises that "In considering social culture, one has to distinguish between denotative and connotative problems of translation" (Newmark, 2001: 98). He establishes further the distinction between cultural, from universal and personal language. To him, there are no translation problems with universals. It is the cultural description of the universal referent that usually poses problems. Thus for Culler, "If language was simply a nomenclature for a set of universal concepts, it would be easy to translate from one language to another... If languages were like this, the task of learning a new language would also be much easier than it is" (Culler, 1976: 21).

There is normally a translation problem with what is often called idiolect. Hence, where there is a cultural focus; "there is a translation problem due to the cultural "gap" or a distance" between the source and target languages" (Newmark, 2001: 24).

On the other hand, in case there are translation problems arising from lack of equivalence at word level, what should the translator do when there is no word in the target language (TL) which expresses the same meaning as the source language (SL) word? The major way out is still manipulation. For Bell:

The choice of a suitable equivalent will always depend not only on the linguistic system or systems being handled by the translator, but also on the way both the writer of the source text and the producer of the target text i.e. the translator, choose to manipulate the linguistic systems in question (Bell, 1991: 18).

Compromise, its seems, should be the result of deliberate decisions taken in light not only of what latitudes are allowed by the SL and TL 
respectively, but also of all the factors that can play a determining role in translation: the nature of the ST, its relationship to SL audiences, the purpose of the TT, its putative audience, and so forth. Only then can the translator have a firm grasp of which aspects of the ST can be sacrificed with the least detriment to the effectiveness of the T'T, both as a rendering of the ST and as a TL text in its own right. This may just be a remedial therapy to the problem since "The words of a language often reflect not so much the reality of the world, but the interests of the people who speak it" (Palmer, 1976: 21).

\section{Conclusion}

We started out by stating that there are social/cultural barriers to translation. These social/cultural barriers infringe on effective translation since the latter is a symbiotic activity which involves the texts to be translated and the one who does the translation. The article further contended that the word social is obliterated by the word culture since social relations or actions take place within a culture. In the course of the discussion through logical analysis, it becomes obvious that compromise is part and parcel of translation. This has implications for effective or perfect translation which seems to be a facade. The article concludes that manipulation or compromise in translation exposes a gap that remains very wide leaving, in its trail, a serious burden on translators not because of their incompetence towards translation per se, but because of cultural diversities of words and language, hence the recommendation that the nearer a translation is to the original words or text in the face of equivalence, the better.

\section{References}

Bell, R. T. (1991). Translation and Translating: Theory and Practice. Essex: Pearson Education.

Blackburn, S. (2009). What do we really know?... London: Quercus.

Blackburn, S. (2005). The Oxford Dictionary of Philosophy. Oxford: Oxford University Press.

Chomsky, N. (1964). "Current Issues in Linguistic Theory" The Structure of Language: Readings in the Philosophy of Language. New Jersey: Prentice-Hall. Culler, J. (1976). Saussure. Glasgow: Fontana/Collins. 
HSS, vol. VI, no. 1 (2017): 77-87

Durkheim, E. (1973). The Rules of Sociological Method. (Trans) Ed. Sarah A. S. and John, H. M. George C. Chicago: Free Press.

Hervey, S. and Higgins, I. (2007). Thinking Translation... London \& New York: Routledge.

Munday, J. (2005). Introducing Translation Studies: Theories and Applications. London \& New York: Routledge.

Newmark, Peter. (2001). About Translation. New York: Multilingual Matters.

Palmer, Frank R. (1976). Semantics. Cambridge: Cambridge University Press.

Shastri, Pratima D. (2012). Fundamental Aspects of Translation. New Delhi: $\mathrm{PH} /$ Learning.

The Longman Encyclopedia (1989). London: Long Group.

Ukpong, D. E. (2016). "Ethical Considerations in Translation." Forthcoming Conference Paper.

\section{Biographical note}

Dominica E. Ukpong teaches French and translation studies in the Department of Foreign Languages, University of Uyo, Nigeria. She graduated from the popular translation school of Abia State University where she earned her doctorate degree. Her areas of interest are culinary translation, ethics in translation and cultural dimensions in translation and tourism studies. Dr. Ukpong has published articles in scholarly journals and has attended conferences. She is a member of UFTAN, FIPF among others. 